\title{
Global coordination: weighted voting
}

JAN-ERIK LANE*

In order to halt the depletion of global ecological capital, a number of different kinds of meetings between Governments of countries in the world has been scheduled. The need for global coordination of environmental policies has become ever more obvious, supported by more and more evidence of the running down of ecological capital. But there are no formal or binding arrangements in sight, as global environmental coordination suffers from high transaction costs (qualitative voting). The $\mathrm{CO}_{2}$ equivalent emissions, resulting in global warming, are driven by the unstoppable economic expansion in the global market economy, employing mainly fossil fuel generated energy, although at the same time lifting sharply the GDP per capita of several emerging countries. Only global environmental coordination on the successful model of the World Band and the IMF (quantitative voting) can stem the rising emissions numbers and stop further environmental degradation. However, the system of weighted voting in the WB and the IMF must be reformed by reducing the excessive voting power disparities, for instance by reducing all member country votes by the cube root expression.

Keywords: global coordination; transaction costs; global economic governance; environmental interdependencies; greenhouse gases; ecological capital; weighted voting; voting power.

JEL Classification: Q32.

\section{INTRODUCTION}

The need for global coordination of environmental policies has become ever more obvious. The UN has engaged in global environmental policy-making during the last two decades, resulting in global meetings with resolutions concerning important principles, like e.g. sustainability. The United National Environment Pro-

\footnotetext{
"Visiting professor at the University of Freiburg in Breisgau. E-mail: janeriklane34@googlemail.com. Submitted: 26/October/2011; Approved: 13/March/2013.
} 
gram (UNEP) is the framework for the United Nations involvement environmental issues at the global and regional level, comprising a mandate is to coordinate towards environmental policy consensus by means of global environment review, bringing emerging issues to the attention of Governments and the international community for action. Yet, the enforcement problematic has not at all been addressed. Environmental coordination lacks a global organisation that can follow up on what happens with all declarations and intentions, monitor real developments in various continents and engage in practical activities that protect global ecological capital.

As the process of globalisation rolls on year in and year out, the states of the world become dependent upon each other. The interdependencies between countries - economically, environmentally and culturally - call for common policy-making, i.e., coordination of decision-making. The often heard call for global governance is only credible, if it can deliver a theory about effective decision-making. However, often global meetings of Governments result in little or nothing, except sometimes non-binding recommendations.

This Marxian contradiction between ONE global economy and environment on the one hand and some 200 states in need of policy coordination in response to the challenges of globalisation is extremely difficult to resolve. On the one hand, the representatives of each and every state will want to have a SAY in global decision-making - the unanimity principle. On the other hand, respecting the will of each of the 200 Governments would lead to staggering transaction costs in negotiations. Is there a way out of the veto-transaction cost problematic that can save global reunions from coordination failures like the summits on Climate Change and environmental protection?

\section{GLOBAL ECONOMIC INTERCONNECTEDNESS: ONE MARKET ECONOMY}

The interconnectedness in the global economy has become so large that any major shock hurts almost all economies in the world. The amount of interaction in the global economy is typically measured with the IMPEX indicator, which divides imports plus exports with the GDP. Diagram 1 shows the constantly growing IMPEX scores for the global economy, which follow closely the expansive trend for global output and world trade.

The close match between the trends in Figure 1 confirms the basic insight in market economics that only free trade can deliver affluence. Global trade and foreign direct investments remain the engine that power global economic expansion. Constantly increasing economic interactions between countries not only cement ONE global economy, but also push the GDP of most countries steadily higher. Growth in aggregate output means that it is easier to fight poverty, but it comes with a most important consequence, namely the increase in $\mathrm{CO}_{2}$ emissions. 


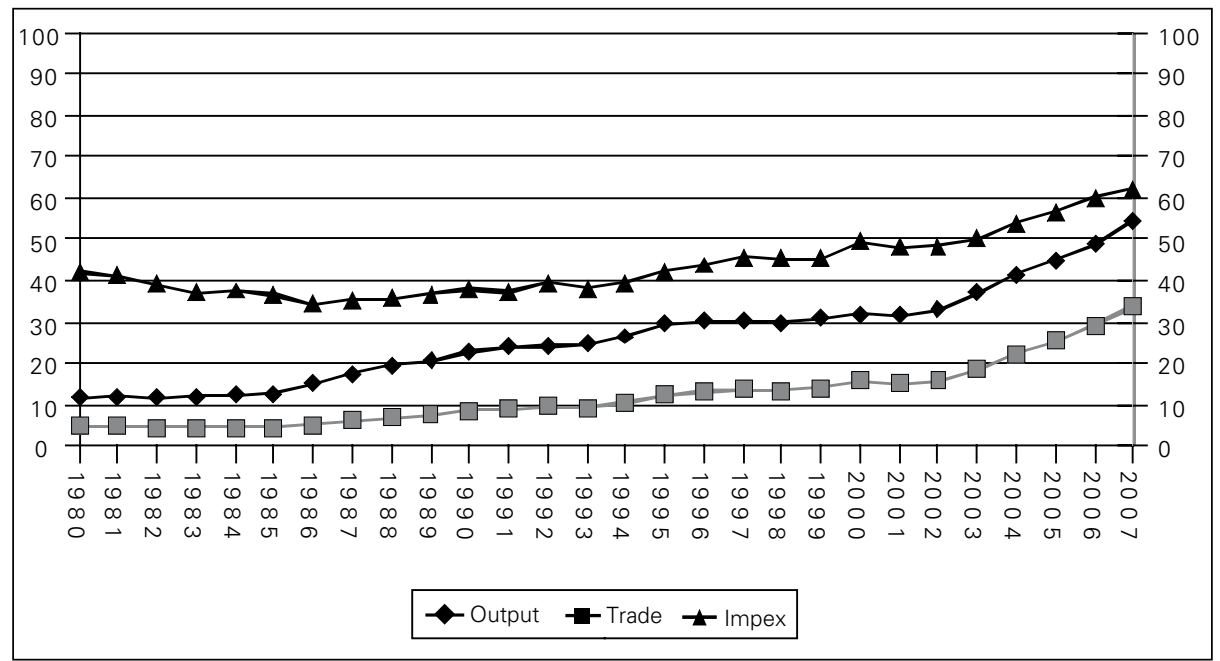

Source: http://www.imf.org/external/pubs/ft/weo/2008/02/weodata/index.aspx

\section{ENVIRONMENTAL INTERDEPENDENCY: $\mathrm{CO}_{2}$ EMISSIONS AS A RESULT OF GDP GROWTH}

The emission of greenhouse gases, as measured by Energy Information Administration, has been on the rise for twenty years. And they are predicted to keep rising considerably in the stylised scenario for the next twenty years. How could all the meetings of the Governments of the world change this trend? The principal difficulty stems from an almost unavoidable green-growth trade-off. The $\mathrm{CO}_{2}$ equivalent emissions are a strict function of economic development, i.e., rising GDP. Economic expansion must have cheap energy, and thus far only the burning of the fossil fuels has provided this vital input to the global market economy. Figure 1 shows the close association between GDP and emissions.

As the emerging economies in Asia, Africa and South America are heading for 5-10 per cent GDP growth yearly, the total emissions must increase, perhaps sharply. One could argue that future GDP expansion will come by energy saving innovations that make possible economic development without burning more fossil fuels. However, Figure 2 shows that the emissions per GDP are not very high in the most affluent countries, meaning that there is little space for savings in emissions per capita.

There are two fundamental trends in the growth-emissions problematic. On the one hand, a higher level of GDP requires more energy that leads to more emissions. On the other hand, a more advanced economy employs less of emissions per GDP unit. It is the first trend that is the strongest in the world today, resulting in an inexorable rise in the global emission of greenhouse gases, believed to the man made cause of global warming syndrome.

If the Governments of the countries of the world are sincere about the ambi- 
Figure 1: Total $\mathrm{CO}_{2}$ Emissions and GDP in Billions

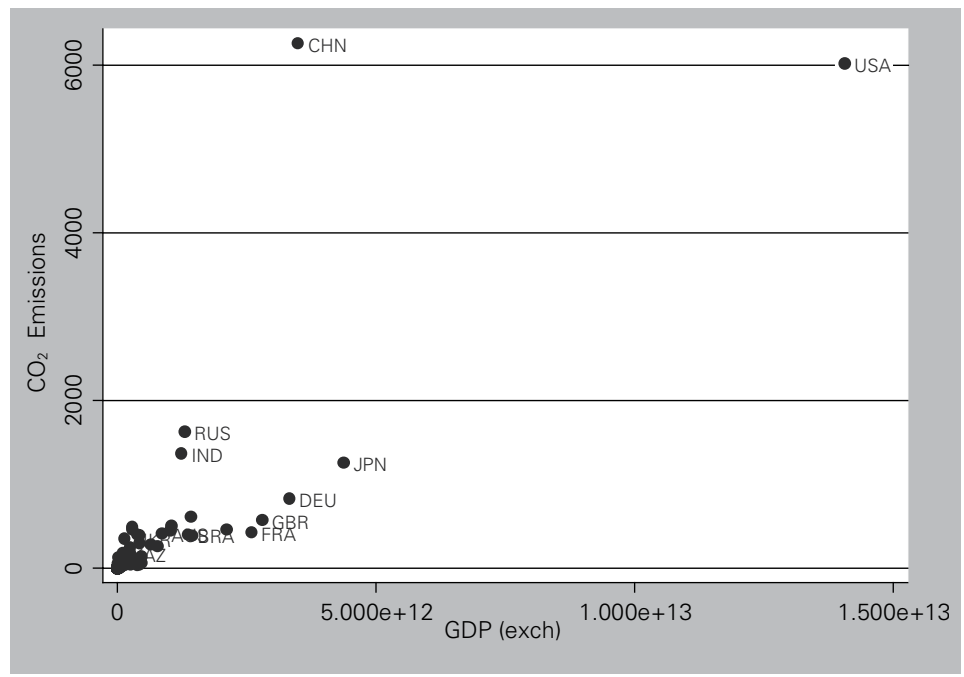

Source: EIA (2010)

Figure 2: Emissions per GDP against total GDP in Billions

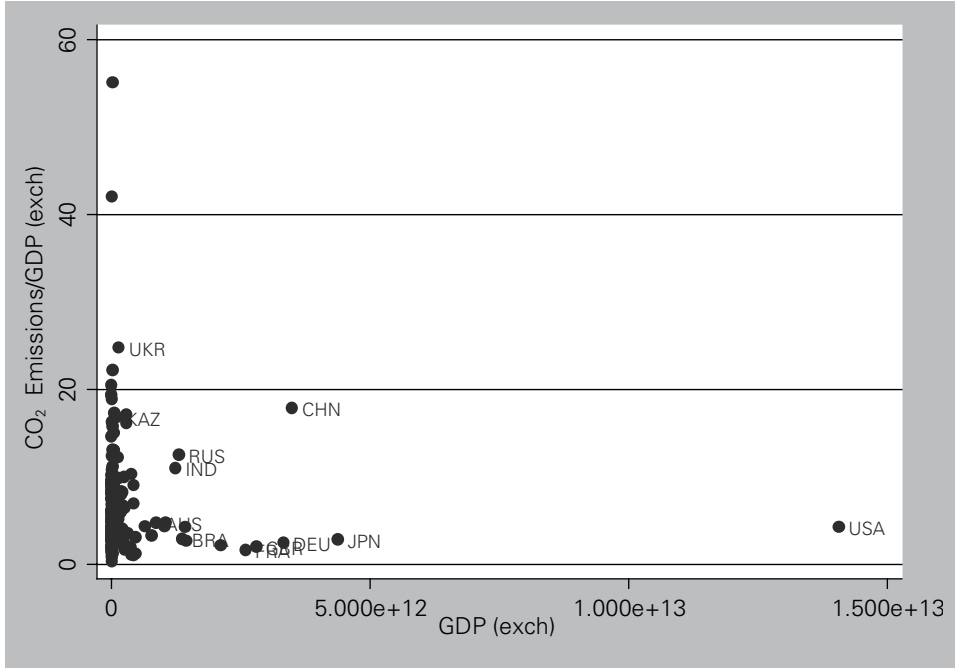

Source: EIA (2010)

tion to stem the progressions of $\mathrm{CO}_{2}$ emissions, then they must create an international organisation that monitors the future trend in emissions and that can decide about counter measures, like a $\mathrm{CO}_{2}$ tax or a carbon emissions trading scheme. But global coordination is extremely difficult, due to the veto-transaction cost problematic. Only two forms of global coordination work effectively, namely the World Bank and the IMF. Why? Because they have overcome unanimity and reduced transaction costs by employing an institution of weighted voting. 
It is an axiom in theories of capitalism and the market economy that they do not constitute self-regulating systems of human interaction. Thus, Max Weber (1978) called attention to the relevance of firm institutionalisation in order to make modern capitalism (the market economy) different from "capitalisme sauvage". As an economic historian of the institutionalist bend, he devoted much effort to pinning down how the rules of the market economy had evolved from other forms of capitalism: rural, feudal and state.

Stiglitz $(2004,2006,2007)$ raises the need to clarify and amplify institutions as modern capitalism has been transformed into one global market economy, thus rendering a bigger role for global economic management by international organizations in order to enhance fair trade and empower Third World countries. Stiglitz calls for radical changes in the market economy itself as a response to the need for achieving justice or global fairness by means of global economic management (Stiglitz, 2007 and 2010; Stiglitz \& Charlton, 2007; Serra \& Stiglitz, 2008; Chang, 2001). At the same time, he recognizes, like Bhagwati (2004) that only the institutionalised global market economy can efficiently create wealth and improve on poverty in the Third World (Stiglitz, Ocampo, Spiegel, Ffrench-Davis \& Nayyar, 2006). What global economic coordination first and foremost needs is a new voting regime.

Two types of voting regimes can be distinguished: quantitative regimes and qualitative regimes. The first is employed by the World Bank and the IMF, while the second is used by the World Trade Organisation (WTO). The World Bank and the IMF with quantitative voting have sharply differentiated voting rights, reflecting the contribution of capital to these organizations. Thus, a few member states have a huge number of votes, whereas other large economies have few votes. This creates a fundamental imbalance in global governance, with the World Bank and the IMF being dominated by the Western powers plus Japan. This imbalance may have been a necessity after the Second World War when China, India, Nigeria and Brazil were extremely poor. But today a redistribution of voting rights is feasible and desirable.

The WTO with qualitative voting is unbalanced in terms of the distribution of votes, but for another reason than the one just suggested. Here, all member countries have the same number of votes: that is, one vote for the US and for Djibouti e.g. - a quite unrealistic situation given the immense differences in trade among the roughly 160 member countries in the WTO. Since the WTO employs a qualified majority and one state-one vote, the small member states receive a voting power that is completely unrelated to their relative size in global trade. This makes the WTO unwieldy (Jones, 2009), blocking further advances in the global trade regime.

In the World Bank and the IMF, the opposite problem exists. Thus, heavy quantitative voting results in the virtual dominance of the so-called "triad" comprising the US, the EU and Japan: see Table 1. 


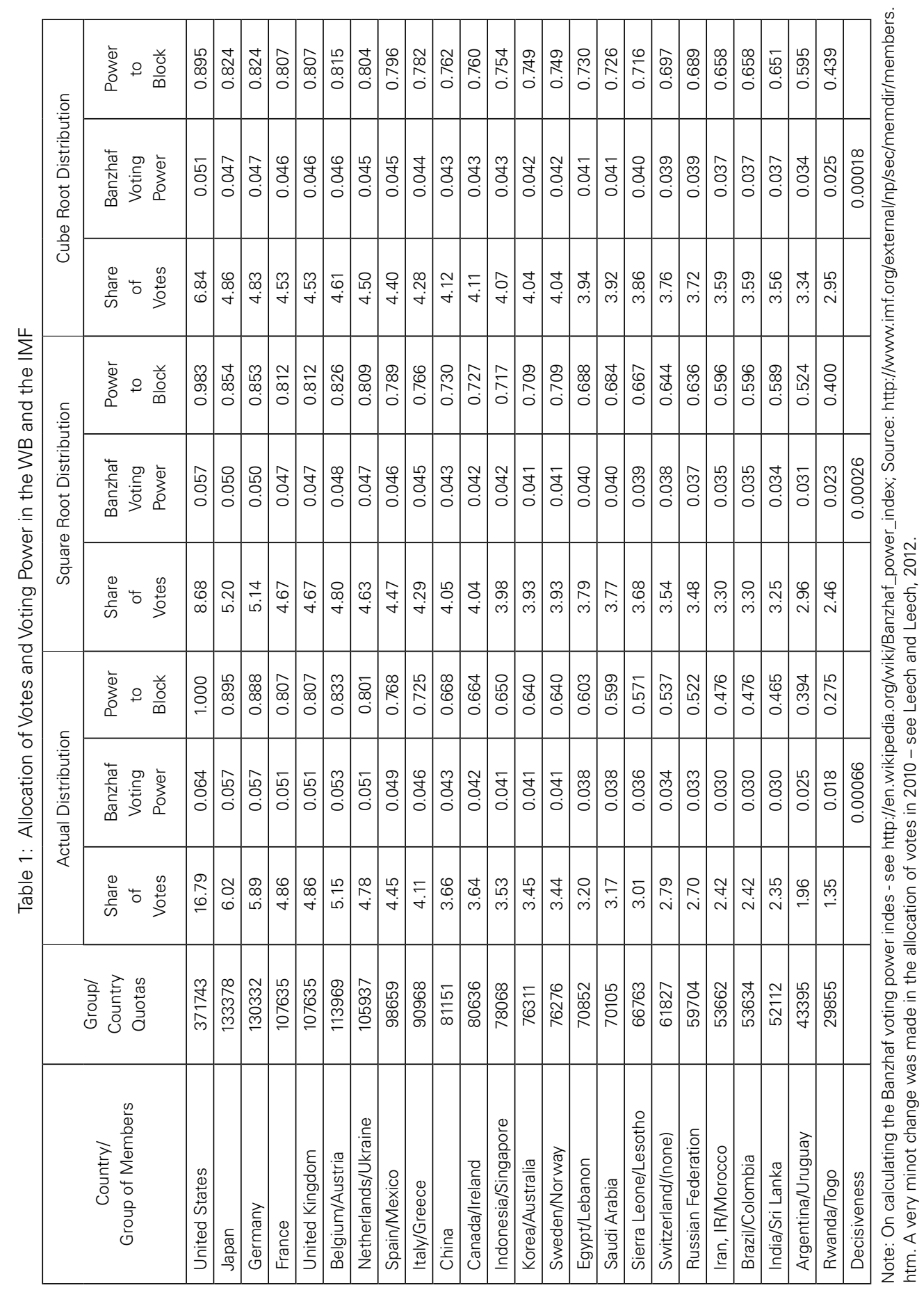


As appears from Table 1, the distribution of votes in both of these organizations is highly skewed to the advantage of the triad. Since these two organizations employ qualified majorities ( $85 \%$ ), the dominance of the three vote-heavy countries becomes complete. The uneven vote distribution has no doubt reflected the situation in the past, but it is no longer in tune with economic realities. The emerging economies are increasingly calling for a balanced composition of these global management bodies. Whereas the World Bank and the IMF should consider reducing the inequalities in vote allocation while giving more votes to the emerging economies, the WTO should reflect on the possibility of introducing some form of quantitative voting. It is easy to present alternative schemes for reducing the immense differences in the allocation of votes by taking, for example, the square root or cube root of the present allocations, as modelled in Table 1. Such a simple institutional reform would preserve policy effectiveness while substantially reducing unjust power inequalities. Even better would to to reduce the high qualified majority requirement at the same time, to for instance $2 / 3^{\text {rd }}$ majorities, as it would increase group decisiveness, reducing transaction costs. In such a reform structure for global coordination, huge emerging market economies like e.g. Brazil and India, would be provided with voting power corresponding to their economic size in the global market places.

\section{CONCLUSION}

If the Stern Review (2007) is correct in calling the $\mathrm{CO}_{2}$ emissions the largest market failure ever for mankind, then the Governments of the countries of the world should be interested in global environmental coordination. Constant meetings of heads of states and premiers have thus far not resulted in any credible policy, halting the increase in greenhouse gases.

A new global environmental board, composed along the model of a revised WB or IMF, could do a lot to counteract environmental degradation globally and the constantly decreasing global ecological capital. It could be financed by the carbon taxes or from the emission rights trading with the surplus going to the funding of the UN operations.

Global environmental coordination must overcome the collective action difficulties typical of state coordination. The voting regime of the WB and the IMF shows that this can be done. Weighted voting is a proper institution for global coordination, but the allocation of voting rights must not be skewed. By reforming the scheme in the WB and the IMF, simply taking the cube root of the present allocation, a viable format for global coordination can be constructed, allowing for certain but not excessive differences in state voting power as well as overcoming the veto-transaction cost problematic, especially if the qualified majority aggregation rule is also reduced somewhat.

The UN framework of UNEP is not delivering effective policies. Only global environmental coordination on the successful model of the World Band and the 
IMF can stem the rising emissions numbers and their projections - quantitative voting reflecting the differences in size between the states of the world. However, the system of weighted voting typical of the WB and the IMF must be reformed when a global ecology organisation is set up.

\section{REFERENCES}

Bhagwati, J. (2004) In Defense of Globalization. New York: Oxford University Press.

Chang, H-J. (2001) (ed.) Joseph Stiglitz and the World Bank: The Rebel Within. London: Anthem Press. EIA (2010). Energy Information Administration: http://www.eia.doe.gov/

Leech, D. (2012) "A New Analysis of A Priori Voting Power in the IMF: Recent Quota Reforms Give Little Cause for Celebration" (with Robert Leech), Warwick Economic Research Papers, no.1001, 2012; forthcoming in Power, voting and voting power: 30 years after, edited by Manfred J Holler and Hannu Nurmi, Springer.

Nordhaus, W.D. (2007) A Review of the Stern Review on the Economics of Climate Change, Journal of Economic Literature, XLV (September): 686-702.

Serra, N. and J.E. Stiglitz (2008) (eds.) The Washington Consensus Reconsidered: Towards a New Global Governance. Oxford: Oxford U.P.

Stern, N. (2007) The Economics of Climate Change (The Stern Review). Cambridge: Cambridge U.P.

Stiglitz, J. E. (2003) Globalization and Its Discontents. New York: W. W. Norton.

Stiglitz, J.E. (2007) Making Globalisation Work. The Next Steps to Global Justice. New York: Penguin.

Stiglitz, J.E. (2010) Freefall: Free Markets and the Sinking of the Global Economy. London and New York: Allen Lane.

Stiglitz, J.E. and Charlton, A. (2007) Fair Trade for All. Oxford: Oxford U.P.

Stiglitz, J., Ocampo, J.A., Spiegel, S., Ffrench-Davis, R. and Deepak Nayyar (2006) Stability with Growth: Macroeconomics, Liberalization and Development. Oxford: Oxford University Press.

Weber, M. (1978) Economy and Society I-II. Berkeley: University of California Press.

Weitzman, M. L. (2007) A Review of the Stern Review on the Economics of Climate Change. Journal of Economic Literature, 45(3): 703-724. 